\title{
Constructing the Marketing Channel of Chinese Opera Films from the Perspective of Communication
}

\author{
Qianhui $X u^{1, a}$, Chenggang $\mathrm{Xu}^{2, \mathrm{~b}, *}$ \\ ${ }^{1}$ Shi Liangcai School of Journalism and Communication, Zhejiang Sci-Tech University, Hangzhou, \\ Zhejiang, 310000, China \\ ${ }^{2}$ College of Economics \& Management, Three Gorges University, Yichang, Hubei, 443002, China \\ annn98@sina.com, ${ }^{\mathrm{a}} \mathrm{mmm98@126.com}$ \\ *Corresponding author
}

Keywords: Chinese opera film, Communication, Marketing channel, Intangible cultural heritage.

\begin{abstract}
Is there no market for Chinese opera films? The disconnection between supply and demand and the absence of effective convection channels may be the real causes for the contraction of market. How can marketing avoid falling into the misconception of "promotion"? The ecology of opera film changes with the improvement of population economic level and quality. Therefore, we believe that opera producers must understand that the audience and the media have changed substantially in order to get out of the dilemma of production and marketing.
\end{abstract}

\section{Introduction}

In China, different from the past, Chinese opera films are considered to be a minority art. The works of creators is to build air castles, out of the market so that are appreciated by a limited audience. What media is suitable for the propaganda and dissemination of opera films and finds herself audience? At least TV media are not optimistic, and the broadcast time is far less than variety shows, TV series, news and other types of programs. Opera works themselves are old subjects, lack of creativity, resulting in opera film away from the audience.

\section{Cognitive misunderstanding}

Many domestic studies have attributed the "niche" phenomenon of opera films to insufficient market demand. Because there is a small audience, market is small. It is believed that "the audience of opera films is mainly concentrated in some high quality people or some local people who speak dialects. In some places, the creation of opera films is an act to fulfill the protection of intangible cultural heritage and anyone is not expected to buy tickets. It is believed that because the market is too small to attract the young people who speak Putonghua in the face of multiculturalism, so they can sell the opera films to the people who are pursuing the diversity of cultural consumption, and get rid of the image of the theater teahouse in the old era. This "high-end oriented" will further make the market smaller. So, the market is really too small, audiences do not like to see opera films?

In fact, Chinese opera filmmakers still focus on themselves and ignore the interest of the audience. They believe that opera film have low box-office income or low ratings because the audience doesn't know how to appreciate it. Even opera producers with the background of state-owned assets don't have to worry about the sale. They believe that they can shoot it and broadcast it. Even they can continue to sell but have no worries about Institutional factors are also primary causes for the disconnection between the production and sale.

At present there is no lack of platforms and means to "promote" opera films in China, but that's not going to bring about a boom in its market. Many people complain that there will be no opera film market in China in the future. They think that if there is no one to watch, there is no market. In fact, there is a lack of talent for the cross-border development of commercial and cultural industries in 
China. These developers think, are people really reluctant to watch opera movies? Has this market been developed to the end?

\section{Media and audience changes}

Nowadays, digital media in China has the characteristics of the whole people. The transformation of media in history always brings new market opportunities, as does the "intangible culture" opera [1].

\subsection{Media popularization}

As changes of the carrier of art, so will its media. Under the conditions of democratization, liberalization and marketization, the communication channels such as blog, micro blog, WeChat, post bar and we-media can enable the "circle of friends" and the public to "share themselves", which has the information communication characteristics of personalized, universalized and autonomization.

The New Media meets the needs of the Chinese audience and is able to conduct one-to-one, cross and radioactive communication between transmitter and recipient.

\subsection{Population stratification}

If subdivided, there is a difference in the aesthetic mindset of the audiences both the cinema and the family to the artworks. In a cinema or theater, the audience represents the public. They could be people of different artistic appreciation. In the atmosphere of family, groups with similar personality, including "circle of friends", may be the "minority" of the audience. When new media appear, the change of communication channel adapts to this differentiation. The audience is divided into "popular" and "elite", "amateur" and "professional" and so on. The changes between them are dynamic and also up and down, horizontal and cross-over.

In the 21st century, with new media as the carrier, Chinese opera films can exert extensive influence through the Internet. The cross, interactive and diffusion effects of communication have changed the pattern of one-way communication and enable Chinese people to obtain unprecedented democratization and liberalization of creation and watch space.

\section{Traditional channel}

What will a professional manager do when he promotes opera film? First, based on market research, rather than subjective imagination, they determine whether there is a market for opera films[2].There are many market investigation methods, the most direct is sampling questionnaire, to understand the acceptance degree and interest tendency and so on, to the different age groups, different occupations, different gender audience. Above methods requires investigators to have a certain professional background. It is only by setting the questionnaire scientifically that accurate results and high reliability can be obtained. Access to network data is another more convenient means. Major video networks in China have opened up opera film columns. We can judge audience's preference tendency and degree to the opera film through the data of the length of time, watching time, age, gender and other data of massive users.

Second, opera films are produced based on market demand. As described above, by market research the real needs of the audience can be understood and then guide production. As an individual creator, there is usually no condition for large-scale market research, but with the help of the column of Chinese local operas in TV station, folk video website, social media BBS, learn about the content, style, length, local opera category, and market size of the opera films that are popular with the audience. Obviously, the traditional media is also used to spread the information of the opera film in a one-way manner, in which the influential target audience in the circle of friends plays a very important role in the communication, as shown in Fig.1. 


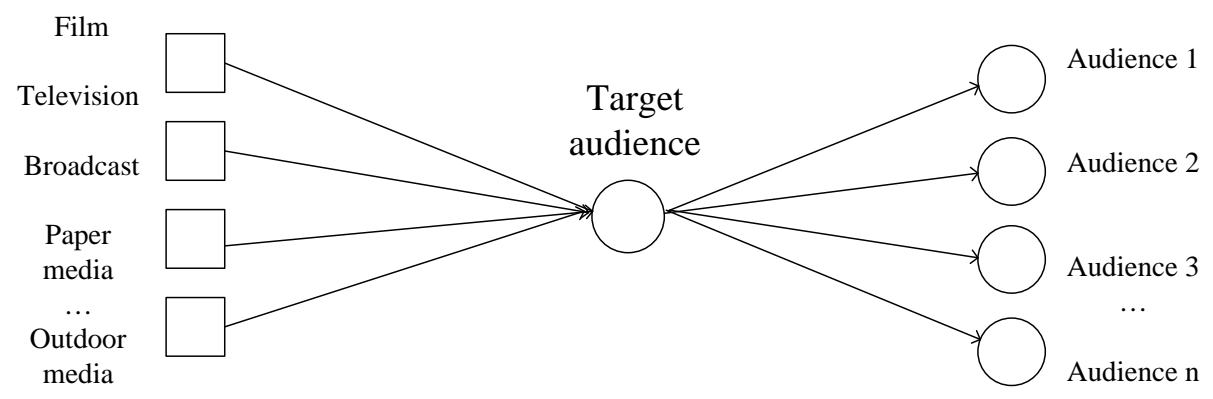

Fig. 1. Separate communication of traditional media and audience

\section{New media channel}

\subsection{Efficacy of WeChat}

WeChat is the most popular social media for Chinese at home and abroad. WeChat can be used for film information dissemination [3]. Because it is faster, wider range, and can complete the function of interaction with the audience, improve the communication efficiency and user interest. WeChat has three characteristics:(1)It mainly focuses on interpersonal communication and establishes communication platform through acquaintances;(2)Through the mobile Internet, we introduce the internetwork, paper, electronic, network phone about opera film information ;(3)Target audience location is accurate and messages achieve viral spread among people with similar interests and hobbies(see Fig.2.). The WeChat public number of many media platforms is showing a good momentum of development in China. WeChat platform is cheap cost, easy to access and suitable for all social classes. It shares online video, related articles, pictures and release schedule of Chinese opera films to your friends. WeChat of the media platform is full of pictures and texts, showing fully the dynamic of the opera film and the artistic characteristics.

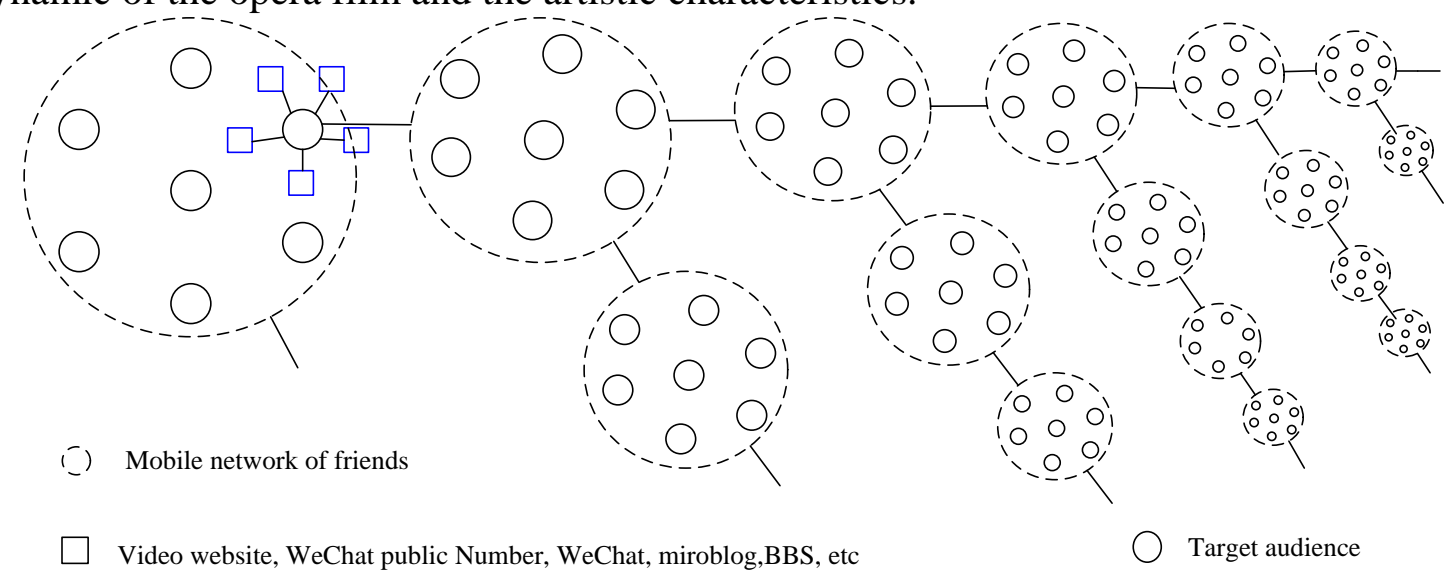

Fig. 2. Schematic diagram of viral communication effect of private community platform

\subsection{Conditions of communication}

Young audience is the cornerstone of the future survival of Chinese opera. Producers have to cater to their psychological trends and tap into their underlying desires before the spread of the virus splits can continue (see Fig. 2). Only when the target audience sees it and feels good will they share it with others. The others also feel very good, will continue to pass on. The content and communication conditions should be :(1) meaningful stories ; (2) passing is an easy thing to do; (3) make use of the existing communication network. 


\section{Comparison of two channels}

Traditional marketing pays more attention on user arrival rates: older audiences, for example, spend more time on cultural consumption of newspapers, magazines, television and radio [4]. In China, many young and middle-aged people, including teenagers and children, are no longer so fond of reading traditional media. So opera videos in modern media, and related articles, especially video sites and WeChat public numbers that have a wider or more influential coverage, can capture the attention of more viewers and readers.

New Media Marketing is a viral Marketing, through WeChat, miroblog, forums, search engines and other means of communication to achieve marketing. Usually, new media can be used to express and disseminate public opinion, so that consumers can identify with certain concepts and views. Merchants can achieve the purpose of publicity and sales.

Traditional marketing forces brand images into our minds through television, film, Internet, magazines and outdoor media advertising. It is one-way output, and with brainwashing propaganda to gain more audiences and potential audiences [5].

Compared with the one-way propaganda of traditional media, the marketing of opera films in new media pays special attention to target audiences. This is very critical starting point for the new media marketing. Who's the target audience? Where he or she can be found? To find target audiences, bidirectional interaction is the most direct and effective way. Similar people come together in groups, and can actively communicate with each other. Depending on this diffusion, opera producers can access more seed audiences.

\section{Conclusion}

From traditional marketing to new media marketing, the most fundamental is to change the thinking: Always starting from the audiences demand and their value of new media, it is crucial to cultivate the audience's sense of participation.

Opera film marketing is a set of systematic concepts, theories and methods that affect the whole process of an organization's operation. In order to truly achieve "marketing," we must begin with a change of concept and identify effective market demands. So guide the creation and production and push the marketable works to the audience.

\section{References}

[1] H.B. Zhou, The mirror opera film in TV and Internet---examples as Beijing Opera and Kunqu Opera, A hundred Schools of Art, Vol.154, pp.51-55, 2017.

[2] R.Peng, From promoting to marketing: the market survival strategy of documentary. Academic Review, Vol.4, pp.70-72, 2016.

[3] Y.Zhu, The inheritance and innovation of Suzhou farce under WeChat environment, Value Engineering, Vol. 07.pp.251-252, 2017.

[4] H.J.Zhang, P. Wang, The Enlightenment of marketing combination tool to film and TV documentary industry. News Enthusiast, Vol.09. (First half month), pp.56-57, 2010.

[5] F.R.Zhang, M.Gao. Literature and art boutique bundles scale management strategy, Frontier Economy and Culture, Vol.169, pp.84-86, 2018. 